\title{
$\mp \quad$ Webs de Museos: Aproximación y valoración de los recursos de información electrónicos de ámbito nacional
}

Susana Limón Rodríguez

Centro de Documentación del IAPH

\section{Consideraciones previas}

Nadie puede dudar ya, a estas alturas, de la repercusión social que tiene Internet. Lo que comenzó casi como un experimento allende los mares, ha pasado a vincular de una forma impactante a todos o casi todos los países del mundo.

La Red de redes alberga, hoy en día, casi todas las disciplinas posibles y existentes, y hasta algunos temas novedosos que se llegan a descubrir sólo en este medio.

Redes académicas, gubernamentales; información variadísima sobre temas que pueden interesar a muy distintos niveles: desde a un investigador que necesita información sobre ciertos temas específicos, hasta a un cibernauta que utiliza la Red como mero divertimento.

En Internet, podemos encontrar la información estructurada de muy diversas formas, según el fin último que se pretenda conseguir.Podemos encontrar páginas web atractivas que nos hagan movernos a través de gráficos, imágenes e iconos, y que apuesten por lo visual y concreto, con el texto preciso y necesario para no aburrir al usuario. Por otra parte, nos encontramos con las páginas web más textuales, donde hay pocos gráficos y fotografías. Algo más similar a un libro en formato electrónico.

Lo ideal, en cualquier caso, es saber combinar una agradable y ágil navegación con una información útil y atractiva, libre de adornos y coherente con la idea que queremos mostrar, y con los datos que el usuario desearía encontrar de nosotros.

Esta gran variedad de temáticas diversas y de tipos de páginas web, se encuentran cada vez en mayor número dentro de la Red.

En este punto es donde debe entrar el documentalista en acción. Con la idea de que Internet no es para expertos, sino para aquellos que están deseosos de pensar y aprender, la labor del documentalista debe centrarse en recopilar y estructurar la información existente en pos del usuario, ya que la proliferación de páginas web, ha puesto de manifiesto la necesidad de contar con una información referencial estructurada. De ahí, que uno de los objetivos planteados en la creación del Servidor Web del Instituto Andaluz del Patrimonio Histórico, haya sido la explotación de las fuentes de información existentes en Internet sobre el ámbito patrimonial, localizando, recopilando y estructurando los recursos por ámbitos temáticos, a nivel nacional e internacional, y proporcionando al usuario un servicio de información denominado Webs de Interés, que ofrece la localización y el acceso directo a servidores, sin necesidad de conocer de antemano su existencia o las direcciones de los mismos.

Ya en números anteriores se han dedicado artículos monográficos sobre algunos temas recopilados como son: Arquitectura, Arte/Historia del Arte o Legislación. En este número hablaremos de los Museos nacionales y su presencia en la Red.

\section{Presencia de los museos en Internet: Valoración previa}

Después de un estudio en profundidad de la presencia de los museos en la Red, llegamos a la conclusión de que estas instituciones, al igual que el arte, encuentran en este medio la horma de su zapato. Internet se ha ido convirtiendo poco a poco en un gran museo virtual que crece cada día. La condición multimedia e hipermedia de este mundo telemático, permite mostrar de forma fácil y original lo que en el medio físico también lo es en distinta medida. Los museos en Internet están abiertos a cualquier persona, y sus fondos son manipulables (se puede cambiar el color o el tamaño), accesibles (se pueden almacenar en diskettes, imprimir, guardar,etc) y relacionables. También es posible consultar los fondos de sus bibliotecas, programar una visita, realizar comentarios sobre las colecciones o adquirir algún recuerdo de la tienda. Es decir, la colección de un museo, o un recorrido específico por el mismo, moviéndose a través de los cuadros, o por épocas y estilos, seduce más a simple vista que leer un Boletín Oficial, sin poner en duda en ningún momento, la utilidad que pueden tener para el usuario.

Por todo esto, estar en Internet ya es un hecho obligado. Los museos, como instituciones culturales que son, deben presentarse en la web con todos los atributos que los 
identifiquen, mostrando una coherencia con su imagen real y sus contenidos. Se trata de asomarse a la página virtual de un museo y poder situarse físicamente en él. Los principales museos del mundo se encuentran desde hace tiempo accesibles vía Internet, y cada vez ofrecen mayores posibilidades a sus usuarios. Los museos españoles comenzaron a incorporarse a Internet hace poco más de dos años, primero tímidamente y luego de forma más decidida.

\section{Metodología}

El estudio realizado de la presencia de los museos en Internet, tanto a nivel nacional como internacional, nos ha llevado a recopilar hasta el momento 284 webs, cuya presentación ha sido estructurada, en primer lugar, separando los museos nacionales de los internacionales, y en segundo lugar, diferenciando entre los nacionales, los que cuentan con una web propia de los que sólo tienen una página informativa.

Lo más inmediato, pues, era establecer una lista de los Museos que ofrecen información disponible en Internet. El primer paso consistió en buscar el mayor número posible de museos que estuvieran accesibles en la Red, con el fin de partir de una visión global y así hacer una selección.

El segundo paso sería la clasificación. Enseguida nos dimos cuenta de que no todos los museos estaban representados de igual modo, con lo que, además de realizar la clasificación geográfica entre los museos de ámbito nacional y los extranjeros, procedimos a separarlos en dos grupos diferentes:

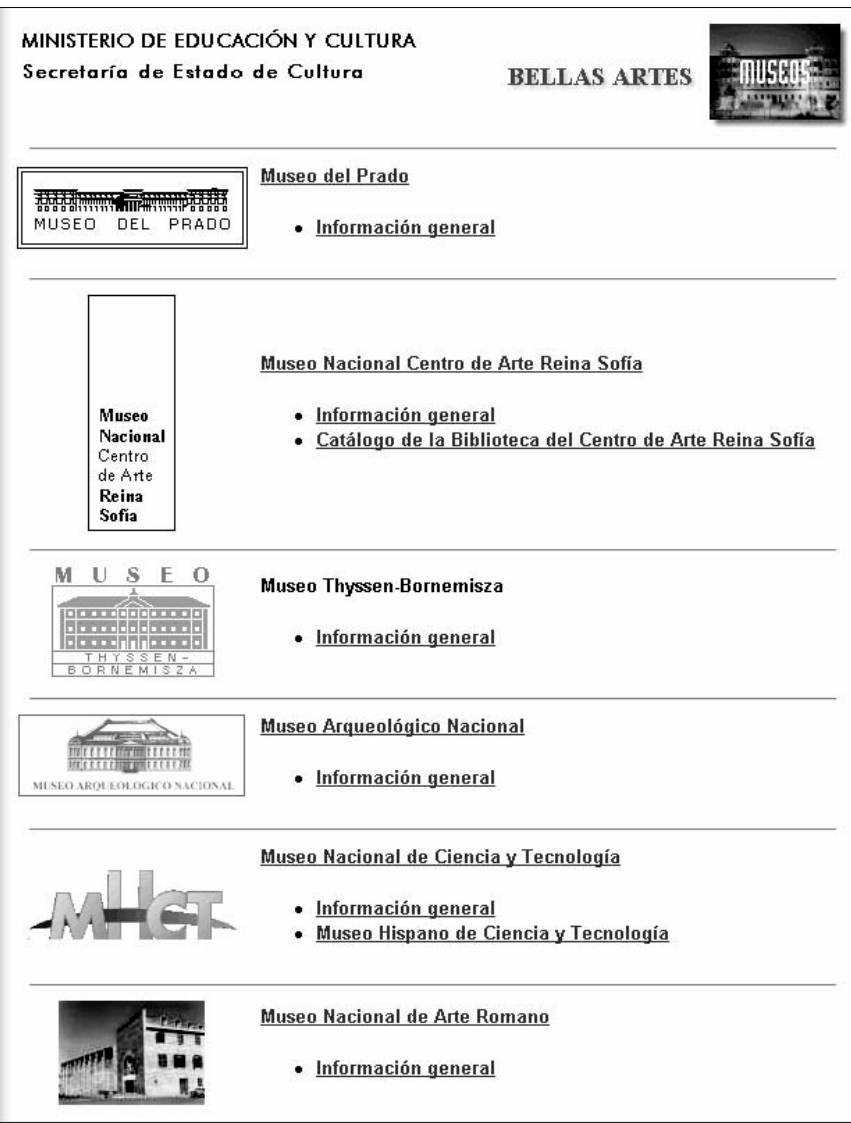

Imagen de los Museos estatales en al web del Ministerio de Cultura
I. Páginas de Museos: donde se encuentran los que sólo ofrecen una breve información general y están albergados en un listado de recursos de interés de otro servidor, como es el caso del Museo de Zaragoza:

http://www.encomix.es/ mendivil/museopza.htm;

el Museo Etnográfico de Tenerife: http://www.cistia.es/cabildotf/calidad/museos004.html,

o el Museo Sorolla de Madrid:

http://www.munidmadrid.es/ayuntamiento/htmlay/museos.html.

Los datos comunes en todos ellos son: Situación, Horario, Teléfonos y una breve descripción, no en todos los casos, de la colección.

2. Webs de Museos: abarca a los que cuentan con web propia, y ofrecen una información más extensa (incluyendo imágenes o recorridos). Estos últimos son los que tienen presencia real en Internet y que pasamos a analizar en el siguiente apartado.

3. Finalmente, y como complemento a esta clasificación, establecimos un apartado alternativo denominado Directorio de Museos, donde se encuentran clasificados por ciudades, provincias o Comunidades Autónomas, como por ejemplo los Museos de Barcelona: http://www.ben.es/castella/barcelon/cultura/musemonu/emuseus $2 . h t m$.

\section{Análisis de algunos museos con Web propia: denominadores comunes $y$ diferenciadores}

No es la pretensión de este artículo catalogar o listar todos aquellos lugares en los que se puede obtener información sobre museos, ya que sería una ardua e interminable tarea sin un fin concreto. Citaremos como ya se ha señalado, algunos ejemplos significativos que nos ayuden a analizar y valorar la calidad y contenidos de los mismos estableciendo comparaciones entre ellos.

Como inicio a este análisis, no se puede olvidar la importancia que en la tarea de búsqueda de recursos de cualquier índole juegan los buscadores especializados en un tema concreto.

En este sentido, el buscador del ICOM, es un buen instrumento para acceder a listados de páginas web ordenadas por temáticas y países, acerca de museos de todo el mundo; http://www.comlab.ox.ac.uk/archive/other/museums.html. Del mismo modo, el directorio de Yahoo, Yahoo Museums, cuenta con un amplio repertorio; http://www.yahoo.com.

Para realizar el análisis, hemos recogido algunos ejemplos de museos de ámbito estatal por ser los más importantes y emblemáticos del país. Estos son: el Museo del Prado, el Museo Nacional Centro de Arte Reina Sofía, Museo Thyssen-Bornemisza. Museo Arqueológico Nacional y Museo Nacional de Arte Romano de Mérida entre otros. También hemos analizado otros ejemplos como el Museo Sefardí de Toledo, La Fundación Joan Miró de Barcelona, el Museo Picasso de Barcelona o el Guggenheim de Bilbao.

Los museos de ámbito estatal cuentan con web propia, pero también se pueden encontrar agrupados dentro de la 
sección dedicada a las Bellas Artes del web del Ministerio de Cultura: http://www.mcu.es/bbaa/museos/bar94.html.

\section{Museo del Prado: http://museoprado.mcu.es/index.html}

La web del Museo del Prado, es, sin duda, la más completa y extensa de todos los museos estudiados. Es también la mejor de los museos españoles y se encuentra entre las mejores del mundo como son las del MOMA de Nueva York, el British Museum de Londres o el Louvre de Paris. La web está estructurada en ocho niveles: Historia, Información General, que recoge planos del museo, información sobre los Departamentos, servicios, y enlaces a otros webs; Visitas, el plato fuerte de la web, donde podemos encontrar bajo el título "Lo que hay que ver", un recorrido por las cincuenta obras más importantes de la colección expuesta. También en este apartado, encontramos una sección sumamente interesante, donde se analiza un cuadro por mes. El mes de Noviembre está dedicado a Fra Angelico y su Anunciación

La sección Actividades, recoge Conferencias, Cursos y Exposiciones Temporales entre otros. También cuenta con un Catálogo de productos, y en la página índice se puede ver la dirección postal y el e-mail, datos básicos de contacto. La navegación es atractiva y fácil, ya que no se pierde de vista el índice principal en ningún momento, y cuenta con traducción a la lengua inglesa, factor importante para su difusión en el extranjero.

Museo Nacional Centro de Arte Reina Sofía: http://museoreinasofia.mcu.es

El Centro de Arte Reina Sofía es uno de los últimos Museos que se han incorporado a la Red. Cuenta como el Museo del Prado con traducción al inglés, y tiene la siguiente botonadura: Colección Permanente, Exposiciones Temporales, Servicios, Actividades, Historia y Consulta automatizada al Catálogo.

La botonadura está muy bien diseñada y favorece la navegación por la web. También incluye dirección postal y e-mail al que enviar mensajes, aunque éste no sirve para reservas, visitas concertadas u otros servicios, por lo que está infrautilizado. El diseño de las páginas concuerda muy bien con la imagen y el carácter vanguardista del museo. El uso del blanco y negro proporciona un efecto muy conseguido. La mejor información que ofrece es el paseo por la colección permanente, que se encuentra dirigido por plantas, salas, autores $y$, finalmente, una selección de obras de los mismos. El paseo por la planta Cuarta (Contemporáneos), y Segunda (Vanguardias Históricas) resulta de sumo interés. Todas las piezas emblemáticas del museo están incluidas: el Guernica de Picasso, La Muchacha de la Ventana de Dalí, etc. La información relativa a las exposiciones temporales y a los servicios del museo,está muy bien estructurada. Merece especial mención el acceso automatizado al catálogo de la Biblioteca, ya que es el único museo que lo ofrece en realidad, aunque se echan de menos los enlaces externos que puedan ampliar y completar el conocimiento del visitante.
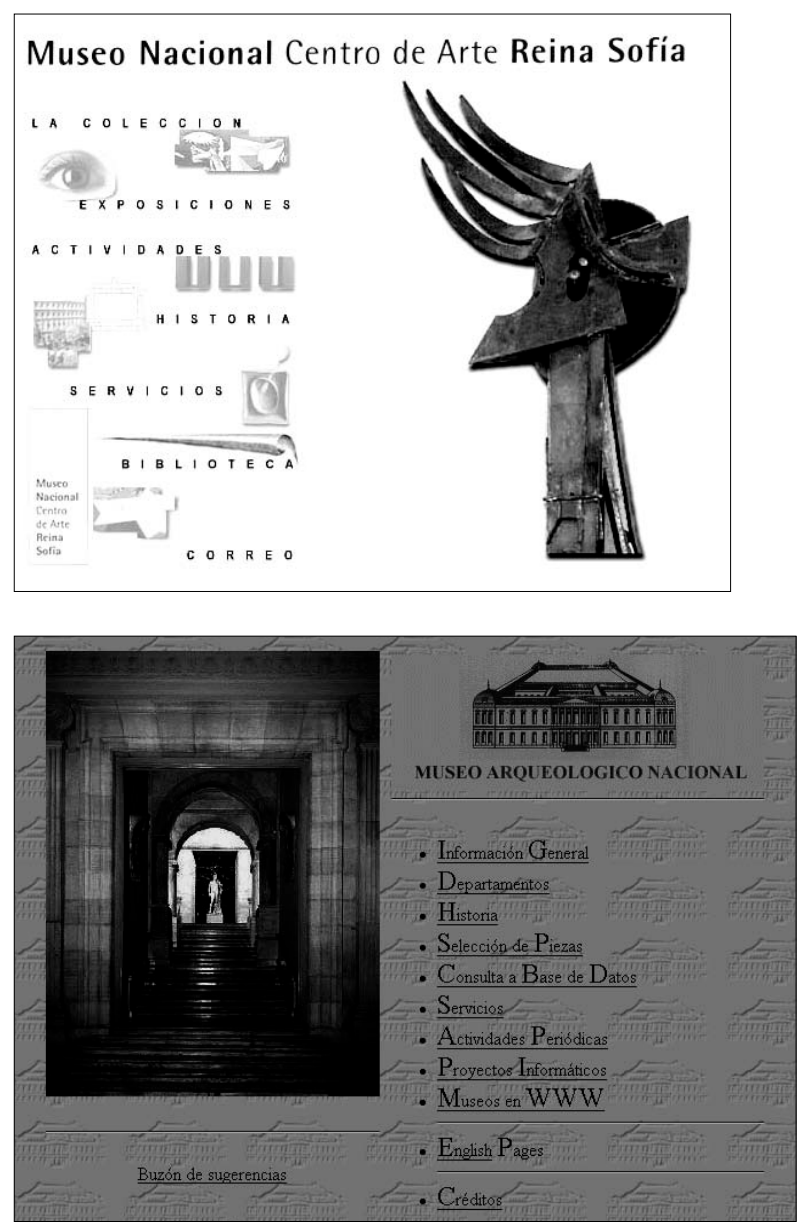

Pantalla principal del web del Museo

Museo Thyssen-Bornemisza: http://www.offcampus.es/museo.thyssen-bornemisza

Nacional Centro de Arte Reina Sofía

Aunque cuenta con traducción al inglés, dirección postal y varios accesos para hacer uso del correo electrónico, el web del Museo Thyssen-Bornemisza es, sin duda, el menos gráfico y por tanto más textual de todos. La página es como un tablón de anuncios donde hay una amplia información dedicada a: horarios, tarifas, grupos, etc; Actividades: exposiciones temporales, conferencias, conciertos; Servicios: tienda-librería, cafetería-restaurante, etc. Sin embargo, hay escasa información sobre la colección del museo y sus piezas. Se habla poco del contenido del mismo, de su historia; y tampoco se alude a la Biblioteca. No hay bibliografía ni enlaces a otros centros de interés.

\section{Museo Arqueológico Nacional: http://www.man.es/index.html}

Cuenta con traducción al inglés y está estructurado en los siguientes apartados: Información general, Departamentos (en construcción), Historia, Selección de piezas con fotografías y descripciones de las mismas, Consulta a una Base de Datos restringida, Servicios, Actividades Periódicas: conciertos, piezas del mes, tardes en el museo, etc., Proyectos informáticos y Museos en la WWW. Esta página es la única que se encuentra alojada en su propio servidor y ha sido creada en el mismo Museo. Fue uno de los primeros museos españoles con página en Internet. Pero la estructura de la página es
Pantalla principal del web del Museo Arqueológico Nacional 
muy plana, aunque es la única que permite acceso a buscadores y a otros recursos en la WWW. El diseño de las páginas no es muy atractivo, pero las imágenes están muy bien tratadas. Lo más importante que ofrece es la posibilidad de acceder a su base de datos( documentación de las piezas del museo). También es importante destacar el apartado dedicado a "Museos en la WWW", que ofrece una serie de enlaces con otros museos accesibles en Internet, aunque se ha quedado un poco desfasado(sólo recoge una pequeña selección). La navegación es lenta, ya que el usuario se ve obligado a volver a la página principal para moverse por todo el recorrido. También se echa en falta un correo electrónico para enviar mensajes y sugerencias. En conjunto, la información que ofrece acierta con el sentido divulgativo que pretende.
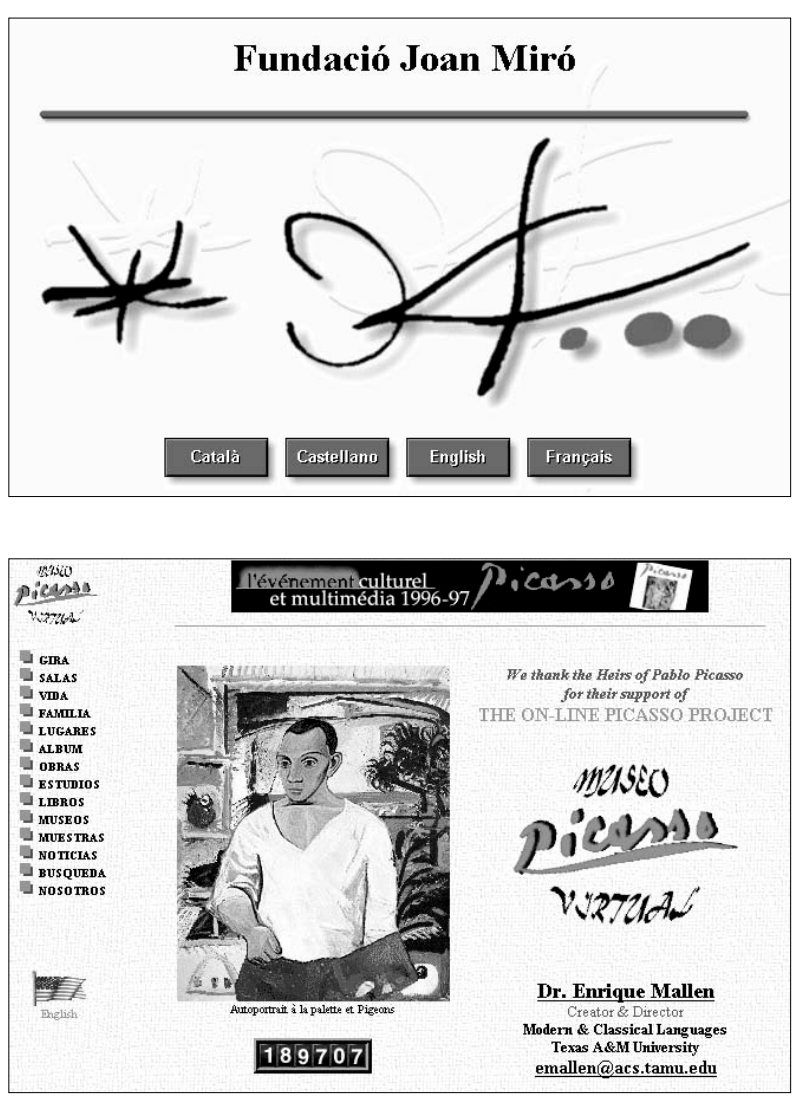

\section{Museo Nacional de Arte Romano de Mérida: http://www.mcu.es/mnar/index.htm}

Cuenta como los anteriores, con la posibilidad de visitar e web en lengua inglesa. Está estructurado en cinco niveles. De entre ellos, cabe destacar como denominador común de los casos anteriores los siguientes botones: Historia, Información General, Actividades y Visita. Dentro de éstas, cabe destacar un recorrido por las plantas del museo reflejados a través de unos planos. En una de ellas se muestras los tipos de edificios romanos; en otra, la colección de cerámica, vidrios, etc., para finalizar por un recorrido por la vida política y administrativa y por la cripta del museo comunicada con los restos arqueológicos de la villa romana. El apartado Actividades, nos muestra la oferta de conferencias, cursos y exposiciones temporales, que no han sido actuali- zadas desde el último trimestre de 1997. En cuanto a su diseño, la utilización de letras blancas sobre fondo gris hace el diseño muy atractivo, pero ralentiza su lectura y resulta de baja calidad en su impresión. La información está bien estructurada aunque intenta reflejar un carácter divulgativo más que de investigación. Es el único museo que incluye una imagen en movimiento aunque sólo con carácter ornamental. Se echa de menos la posibilidad de acceso a catálogos y un recorrido selectivo por las piezas del museo. De igual modo, carece de un apartado de enlaces externos a otros servidores. Pero en general, refleja de un modo positivo la colección y la impronta de la Roma Clásica.

\section{Museo Sefardí de Toledo: http://www.servicom.es/museosefardi}

Web patrocinada por la Asociación de Amigos del Museo, cuenta, para empezar con un e-mail y una dirección postal. En total, tiene ocho páginas y seis imágenes donde refleja las siguientes informaciones: Información general, Senvicios, Actividades del 98 y una visita guiada por la Sinagoga del Tránsito y el Museo.

La resolución de las imágenes fotográficas es buena y el de las páginas en general, bastante agradable.Cuenta con un logotipo de simbología sefardí.La visita por el Museo, resulta muy breve y descriptivo, echando en falta un recorrido más dinámico y gráfico, aunque la información que muestra es bastante práctica. En definitiva, es un web breve pero correcto.

\section{Fundación Joan Miró: http://www.ben.fjmiro.es}

Centrado en su totalidad en la persona del pintor, la web se encuentra dividida en dos caminos distintos. Por un lado, la Biografía del autor reflejada a través de sus épocas pictóricas, y por otro lado, la muestra de la colección dividida según sus etapas, con un listado de obras que muestran la fotografía y una descripción de la misma. Está muy bien resuelto y consigue su fin: mostrar la obra del autor que contiene la Fundación.

\section{Museo Picasso de Barcelona: http://www.tamu.edu/mocl/picasso}

Al entrar en el Museo Picasso, nos encontramos de antemano con un buen número de niveles informativos de gran interés, centrados todos ellos en la vida y obra del pintor. Llama la atención el hecho de que el web aparezca en inglés y que el idioma opcional sea el español. Por lo general, el índice permanece siempre fijo para facilitar la navegación del visitante, aunque no siempre ocurre, y hay que volver hacia atrás varias veces. Cuenta por ejemplo, con un apartado denominado Gira que recorre la vida del artista por años, y otro como es Salas, que muestra una obra emblemática de cada año. La Vida muestra sus datos biográficos, y Lugares, un recorrido geográfico por todos los sitios de Francia que tuvieron algo que ver con el autor. También cuenta con opción de búsqueda, relación de sitios de interés, Noticias y muchos otros apartados de gran variedad informativa. 


\section{Museo Guggenheim de Bilbao: http://www.guggenheim.org}

Desde un primer momento, el web se presenta en lengua inglesa, sin posibilidad de traducción al castellano, algo chocante por ser un museo situado dentro de la geografía española. El diseño está acorde con el de la mayoría de los museos de arte contemporáneo. Dentro de una rueda o espiral, se sitúan las entradas con una fotografía representativa de los diferentes museos Guggenheim del mundo: Berlín, New York, o Venecia. Al entrar en el de Bilbao, nos encontramos con una fotografía y dos entradas textuales: una de información general, y otra de exposiciones. La información que hay detrás, sin embargo, es muy breve y concisa, tanto para mostrar los datos básicos de horarios,etc, como para describir los contenidos de la colección. Muestra la dirección postal y los teléfonos de contacto, pero carece de correo electrónico. Por lo general, la imagen que proyecta el museo a través de su web, no está en consonancia con el prestigio de la institución.

\section{Panorama general y conclusiones}

Trás el estudio realizado, nos damos cuenta que actualmente existe en Internet una enorme muestra de museos de todo tipo, extensión y contenidos. La imagen que nos muestran es también diferente. Los dedicados al Arte Moderno y Contemporáneo son los que han conseguido un diseño más atractivo como son la Fundación Joan Miró y el Museo Picasso de Barcelona. Por el contrario, los Museos de Bellas Artes, Arqueología y Artes Decorativas son los más estáticos y de diseño más convencional.

En general, pocos museos dan acceso a la biblioteca, y todavía menos facilitan el acceso a sus fondos.También llama la atención el escaso número de enlaces externos con los que cuentan. En general, todos presentan la posibilidad de traducción a un segundo idioma, que por lo general es el inglés.

Como conclusión, es evidente la presencia cada vez mayor de los museos españoles en Internet. La demanda cultural hace que cada vez se incorporen en mayor número, asegu-

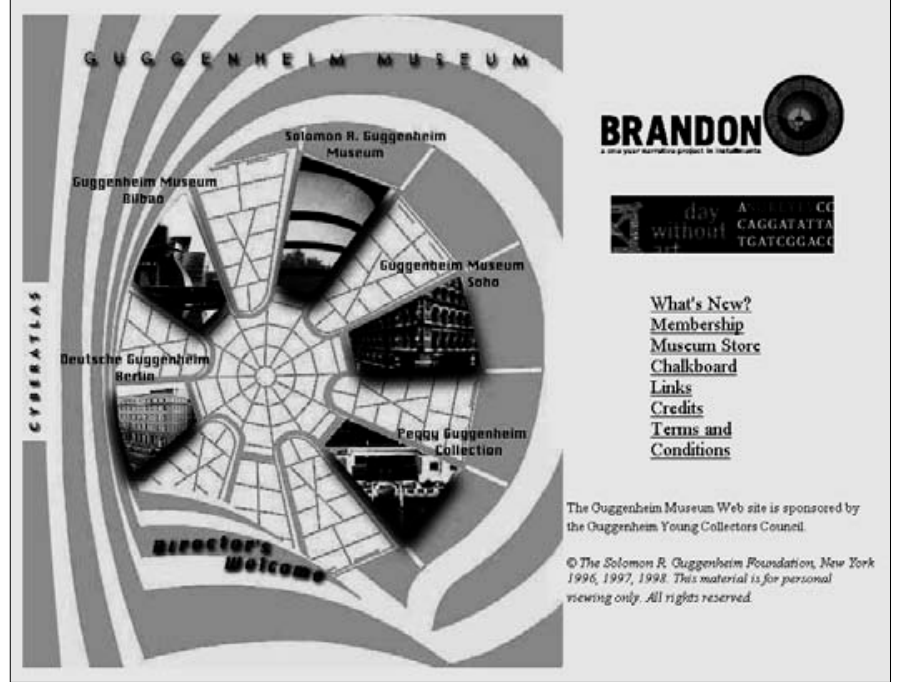

rando la calidad de los recursos museísticos en Internet para los próximos años.

Pero este interés no siempre se demuestra de la misma forma por parte de las instituciones. Mientras unos han cargado las páginas hace tiempo y no han renovado su información en meses, otros, utilizan la página como un gran "tablón de anuncios" más que como un instrumento de divulgación y de información especializada. Hay en general, poca información para investigadores, como son acceso a OPACs o a Base de Datos.

Sin embargo, es cierto que la integración en la Red es definitiva, y que entre los museos españoles existen notables ejemplos de páginas bien hechas, y con una inteligente organización de la información.

Nota:

en la página web del IAPH:

http://www.iaph.caan.es, en la sección dedicada a Webs de Museos: http://www.iaph.caan.es/museos.html, se puede encontrar el listado de direcciones mencionado en este artículo. Dicho listado está en este momento en proceso de actualización.
BUENO, Segio: Arte:Internet, plataforma creativa y expositiva de los artistas del próximo milenio, en EN L@ RED, № I.I2, PP. | 4-22.

GARCÍA LLEÓ, Juan A.: El arte en las Redes. Libros Para Siempre.

HARLEY, Hahn; RICK Stout. Como trabajar en Internet. McGraw-Hill/Interamericana de España, S.A., Madrid, 1996.
LÓPEZ DE PRADO, Rosario. Museos en Internet: análisis de recursos documentales, en Actas VI Jornadas Españolas de Documentación FESABID 98.

MESO AYERDI, Koldo: Arte en Internet. Anaya Multimedia, Madrid 1997. 